\title{
CIDI 2017 \\ Do Artesanal ao Tecnológico: Prototipagem Rápida na construção de um personagem para curta-metragem em stop motion
}

\author{
From Craft to Technological: Rapid Prototyping for building a stop motion character \\ in a short film
}

\author{
Nurian Brandão, Vivian Herzog, Flavio Andalo, Milton Luiz Horn Vieira
}

animação, stop motion, prototipagem rápida, design de personagem.

Este artigo busca observar o uso da prototipagem rápida dentro do âmbito da animação em stop motion, suas especificidades e a relação entre material impresso e movimento criado. Através da análise das mudanças nas etapas de construção das expressões faciais da personagem Alicia podemos observar o desenvolvimento da produção artesanal para a tecnológica presentes no curta-metragem em stop motion, Almofada de Penas.

animation, stop motion, rapid prototyping, concept design

The main purpose of this article is to observe the use of rapid prototyping within the scope of stop motion animation, its specificities and the relation between the printed material and the movement created. Analyzing the changes in the facial expressions construction stages of the character Alicia we can observe the craft production development into today's technology in the stop motion short film called "Almofada de Penas".

\section{Introdução}

Segundo Barry J. C. Purves (2011) no final do século XIX George Méliès foi responsável pela descoberta do recurso de parar a câmera e continuar a filmagem após uma substituição, ou seja, a trucagem de câmera, dando os primeiros passos para o desenvolvimento da técnica de stop motion. Seu filme Les 400 Farces du Diable (1906) foi totalmente feito em stop motion, o que normalmente não acontecia em suas produções, já que Méliès utilizava a técnica como efeitos especiais para alcançar as ilusões de movimento e mudanças de ações. A linguagem do stop motion remete ao desejo de dar vida a objetos inanimados, "[stop motion] poderia ser definido como a técnica de criar a ilusão de movimento ou desempenho por meio da gravação, quadro a quadro, da manipulação de um objeto sólido, boneco ou imagem de recorte em um cenário físico espacial" (PURVES, 2011, p. 06). As animações do russo Ladislas Starevich se destacam por utilizarem insetos mortos como protagonistas, dando vida a uma matéria morta, como em A vingança do cameraman (1912), onde baratas e besouros são os personagens principais da trama. Segundo Purves (2011) as animações que marcam o início do stop motion como uma técnica e uma linguagem com especificidades de ilustrar contos e fábulas, histórias imaginárias e oníricas construídas com objetos palpáveis e materiais físicos, nos levam a pensar o que seriam os elementos ontológicos de sua constituição. Já que possuem características como a possibilidade de expressar conceitos e ideias através de objetos físicos com textura, cor e materialidade palpável que deixa evidente por vezes a interferência e a marca da mão do animador. Esta marca pode estar evidente como vestígios deixados na matéria utilizada para dar vida e movimento aos personagens de uma história assim como figura uma espécie de presença implícita dada pela atuação e manipulação dos objetos movidos pelo artista.

De acordo com Purves (2011) George Pál, animador de origem húngara, se tornou conhecido pela série Puppetoons (1945) nos anos 1950, onde empregou a metodologia de substituição que permitiu padronizar e acelerar a produção em stop motion. A animação de substituição sugere movimento através da troca total de um personagem por outro, ou de elementos do rosto, com a intenção de mudança de expressões e na utilização para o lip sync'1. Priebe (2010) sugere que a substituição "[...] cresceu a partir da lógica por trás da animação

1 Lip sync: é a sincronia dos lábios com a fala.

Anais do $8^{\circ}$ CIDI e 8 CONGIC

Guilherme Santa Rosa; Cristina Portugal (orgs.)

Sociedade Brasileira de Design da Informação - SBDI

Natal | Brasil | 2017

ISBN 978-85-212-1305-5
Proceedings of the $8^{\text {th }}$ CIDI and $8^{\text {th }}$ CONGIC

Guilherme Santa Rosa; Cristina Portugal (orgs.)

Sociedade Brasileira de Design da Informação - SBDI

Natal| Brazil | 2017

ISBN 978-85-212-1305-5 
desenhada à mão, onde cada quadro consistia em um desenho que era diferente do anterior, e cada desenho foi substituído sob a câmera para fotografar" (2010. p. 139) (tradução livre do autor). Anos mais tarde, a técnica de substituição ressurge nos filmes do diretor Henry Selick, O Estranho Mundo de Jack, 1993 e James e o Pêssego Gigante, 1996, na construção de seus personagens. Nestes casos, os encaixes da cabeça foram equipados com imãs para ajudar na fixação dos rostos. A fluidez das expressões dos personagens obtida através de substituição dos rostos é uma das vantagens da técnica de substituição. O desafio por trás da técnica é a enorme quantidade de trabalho envolvido em esculpir e pintar cada peça individualmente a mão, além de mantê-los devidamente encaixados na hora de fotografar.

Animação de substituição no rosto pode ser incrivelmente simples. Mas para fazer animações reais para mostrar emoção e reação se movendo através do rosto do personagem - você precisa de um monte de peças de substituição que, tradicionalmente, tem sido um processo demorado e caro devido a toda escultura e pintura envolvida. (ALGER, 2010. p. 47) (tradução livre do autor).

Atualmente tal concepção sofreu alterações com o surgimento da prototipagem rápida. Esta técnica consiste em modelar objetos em um programa 3D e produzi-los em peças físicas através da impressão em 3D. Conforme Hod Lipson e Melba Kurman (2013) relatam, no decorrer da história da criação de protótipos retiramos a matéria-prima para criar objetos físicos, ou, criamos moldes para originar novas formas. A fabricação aditiva, nome técnico da impressora 3D, funciona a partir do empilhamento em camadas de matéria-prima. Este processo surgiu na animação stop motion como suporte na etapa de criação das expressões dos personagens possibilitando a criação de características faciais intercambiáveis, como: sobrancelhas, olhos, narizes e bocas. Para Ken A. Pribe (2010) a variedade de expressões se dá a partir da divisão do rosto em duas metades, superior e inferior, de modo que os movimentos da boca podem ser combinados com os movimentos da sobrancelha criando diferentes fisionomias. Jed Alger (2010) relata que o responsável por introduzir o uso da prototipagem rápida na produção de filmes de stop motion foi Brian McLean, que se deparou com uma impressora 3D no departamento de design industrial da California College of Art and Crafts enquanto dava aulas de escultura: "Isso é perfeito para rostos de substituição" (2010. p. 48). Ele trouxe esta ideia para dentro dos estúdios LAIKA, que logo no primeiro filme, Coraline (2009), retomou o velho estilo de animação de substituição facial e o colocou novamente no século XXI usando a técnica de prototipagem rápida, descreveu Pribe (2010). O filme Minhocas (2013), dirigido por Paolo Conti, da produtora Animaking, foi o primeiro longa-metragem de animação em stop motion feito no Brasil e utilizou uma impressora em $3 D$ na sua produção. $O$ processo serviu para fazer as bocas e expressões dos personagens, foram produzidas mais de 1400 bocas, facilitando a sincronia entre os áudios com diálogos e os movimentos da boca, segundo as informações do relatório do Anima Mundi (2014).

Atualmente no Brasil, o curta-metragem Almofada de Penas do diretor Joseph Specker Nys, utiliza a técnica de prototipagem rápida na criação das faces de seus personagens. Através do $b^{b} \log ^{2}$ do curta-metragem podemos observar uma linha do tempo da modificação na construção dos personagens, em que conseguimos visualizar que o filme vem sofrendo mudanças nesta etapa. No inicio, as faces foram totalmente modeladas artesanalmente e depois passaram a ser produzidas com a ajuda da tecnologia de impressão 3D. Os métodos artesanais de criação dos personagens em stop motion são feitos através da modelagem de esculturas e moldes feitos a mão. Tendo em vista que a personagem Alicia durante a história sofre mudanças psicológicas, estas precisam estar evidentes no gesto corporal e nas expressões faciais para que seus sentimentos possam ser percebidos pelo espectador. No atual momento a produção do curta-metragem se encontra em andamento e é através do contato direto com o diretor Nys e do acesso ao blog do filme que estão disponíveis as fotografias e testes de animações das etapas de construção da personagem.

Neste contexto, a problemática deste artigo levanta as seguintes questões: em que medida a prototipagem rápida pode apresentar e se relacionar com características fundamentais do stop motion tradicional. Assim, o objeto de estudo consiste em observar as relações dos processos distintos transcorridos no fazer da personagem Alicia no curta-metragem Almofada de Penas, que perpassam por modos artesanais a processos tecnológicos que abarcam a prototipagem rápida.

\footnotetext{
2 Disponível em: <http://almofadadepenas.tumblr.com/> 10/07/ 2017.
} 
Movido por estes questionamentos o primeiro tópico deste estudo aborda as etapas do processo de produção dos rostos de substituição da personagem Alicia, observando como se sucederam os processos de realização e os motivos que levaram as mudanças nas técnicas utilizadas. Em seguida é feita uma análise das expressões de prototipagem rápida da Alicia, comparando-as com as peças resultantes do processo feito com moldes artesanais sem uso de impressora $3 D$. Por fim as análises buscam observar como o processo de prototipagem rápida se relaciona com as questões características do stop motion.

\section{Observações sobre o processo de realização da personagem Alicia}

Em 14 de abril de 2012, foi a primeira postagem de Joseph Specker Nys em seu blog, em que anunciou sua "[...] ousada aventura: um curta-metragem com a técnica de stop motion em homenagem ao conto El Almohadon de Plumas, do escritor uruguaio Horácio Quiroga." (NYS, 2012). Nys nasceu no Uruguai e foi criado no ateliê de cerâmica de sua mãe. Foi a partir deste contato que ele tomou gosto pelas artes. Estudou por um ano na Espanha onde aprendeu sobre roteiro e animação e foi a partir desta experiência que decidiu começar com o seu projeto, Almofada de Penas. O conto de Horácio Quiroga, consta no livro em Cuentos de amor, de locura y de muerte de 1917, e retrata os conflitos de um casal recém-casados. Jordão e Alicia se amam, mas a realidade deste casamento não vai corresponder ao idealismo de almas gêmeas, e esta desilusão acaba por levar Alicia a morte. A tristeza da personagem e o fato de sua alegria e vontade de viver estar sendo sugada por uma relação infeliz aparecem nas características visuais escolhidas para o curta-metragem no que diz respeito ao cenário, a confecção dos personagens e figurino, uma vez que a história está ambientada no início do século XX.

Dentro dos processos de criação de faces, segundo Alger (2010), podemos dizer que existem três maneiras para animar um rosto em stop motion: Claymation, em que é possível modelar o rosto em materiais moldáveis como a argila, plastilina, entre outros, e ir modificandoo; cabeça mecânica, em que geralmente uma capa de material flexível, tal como espuma de látex ou de silicone é colocada sobre um complexo de engrenagens que são manipulados para mudar a expressão do personagem; substituição, que consiste em substituir uma face por outra semelhante, dando a sensação de movimento. No caso do Almofada de Penas, a substituição foi o método escolhido para ser usado na animação das faces dos personagens.

Através de uma entrevista ${ }^{3}$ com o diretor Nys realizada no set de produção do curtametragem, foi possível observar e entender como sucedeu todo o procedimento de construção dos personagens. Nesta visita conhecemos o método final de confecção das faces de substituição para a personagem Alicia, que passou por duas técnicas distintas. O processo foi iniciado pela técnica artesanal em que os rostos foram esculpidos manualmente e replicados através de moldes, posteriormente foi substituído pela prototipagem rápida.

A primeira técnica utilizada na concepção da face se deu através de moldes. Moldes servem para produzir réplicas da escultura original. São muito usados para revestir a armadura com o formato do corpo e para criar mãos e pés. Segundo Susannah Shaw (2012) existem dois tipos de molde: rígidos ou flexíveis. "A regra geral é: se estiver fundindo uma peça rígida, você precisará de um molde flexível (silicone) e, se estiver produzindo uma peça flexível, precisará de um molde rígido (resina, gesso ou fibra de vidro)." (2012, p. 83). No processo de criação das faces da personagem Alicia, foram utilizados os dois tipos de moldes. Em entrevista, o diretor relata que não tinha conhecimento no primeiro momento e tudo foi feito na base da experimentação. Ele queria aprender sobre moldes e foi a partir de um curso no sul de Florianópolis voltado para o design, que Nys começou a primeira etapa de construção das expressões de Alicia.

\footnotetext{
${ }^{3}$ Diponível em: <http://almofadadepenas.tumblr.com/post/162599991941/entrevista-realizada-pela-bacharel-nurianbrand\%C3\%A30 > 10/07/ 2017.
} 
Figuras 01: Primeiras expressões criadas a partir de moldes. (usado com a permissão de Joseph).

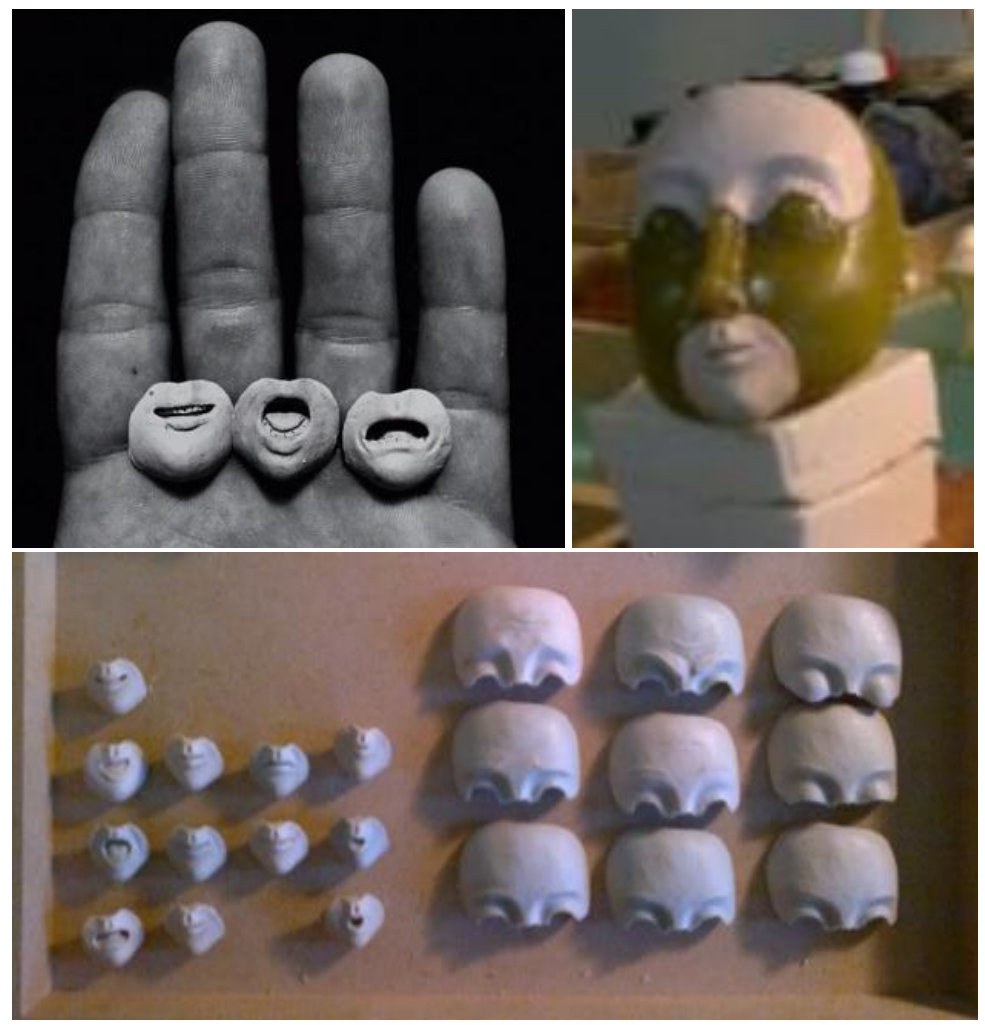

Nesta fase, primeiramente, foi criado um molde de silicone do rosto esculpido em clay da personagem Alicia. O objetivo era fazer a peça principal da cabeça oca para receber os encaixes das expressões, figura 01. Então, foi preciso fazer rotomoldagem ${ }^{4} \mathrm{com}$ o molde de silicone, girando-os cerca de três horas, sem parar, até a resina deixar de ser líquida. A partir dessa peça foi possível modelar todas as bocas em clay. A divisão do rosto foi feita em sobrancelha e boca, deixando o nariz e as bochechas de fora. Tendo como referência o personagem Freud, da animação no programa Afinal, o que querem as mulheres? (2010) da Rede Globo, confeccionado por Luciano Amaral, que possuía 10 testas e 21 bocas, segundo a própria emissora. Conforme o depoimento em entrevista: "O encaixe das bocas era por baixo da barba. Essa era a única referência que eu tinha visto" (Nys, 2017). Terminada a etapa de esculturas das bocas, foram feitas peças de resina a partir de moldes em silicone. Foi nesta etapa que Nys percebeu que esse sistema não funcionou para os propósitos necessários. Pois quando as bocas em resina foram encaixadas na cabeça principal, existia uma grande diferença de tamanho. Todas as peças tinham encolhido no processo. Os diversos moldes, peças em resina, encaixes, dias e dias de modelagem dos diferentes movimentos de sobrancelha e lábios viraram obsoletos. "Quando você tira um molde de silicone, o silicone já encolhe um pouquinho, e quando você coloca a peça de resina neste molde de silicone ela também vai encolher um pouco. Nunca fica exatamente do tamanho da peça original" (Nys, 2017).

Em julho de 2012 Nys encontrou um novo método para a produção dos encaixes das expressões dos personagens, ainda, a partir de moldes. Foi depois de ver o trabalho dos ingleses Joshua Flynn e Nathan Flynn que Nys resolveu entrar em contato com eles para tirar dúvidas sobre o processo e os materiais utilizados. Na técnica utilizada pelos Flynn as peças de substituição das expressões dos personagens são divididas na linha dos olhos, o que ajuda na pós-produção com menos linhas para serem apagadas. Baseando-se nos irmãos, Nys iniciou criando, a partir da escultura original da personagem, um molde da cabeça de Alicia. $O$ processo consistiu em fazer uma camada fina de resina F16 neste molde da cabeça da personagem. O resultado deste método culminou em um plástico fino e resistente, com cor amarelada que demora em torno de sete minutos para catalisar, figura 02. Ela foi cortada com

\footnotetext{
4 Termo utilizado pelo animador que significa fazer uma moldagem rotacional, ou seja, girar o molde até o material
} injetado secar, com o intuito de criar uma peça oca. 


\section{CIDI 2017 告 cold

uma serra fio de cabelo, em um recorte que separa a frente do rosto dá parte de trás da cabeça. A parte de trás é onde as peças de substituição vão ser encaixadas. O seu interior foi feito com epoxi e o encaixe para os olhos de silicone. Foi preciso de massa epoxi Milliput para corrigir as imperfeições e fazer o encaixe perfeito.

Figura 02: Segunda modelagem das expressões a partir de moldes. (usado com a permissão de Joseph).
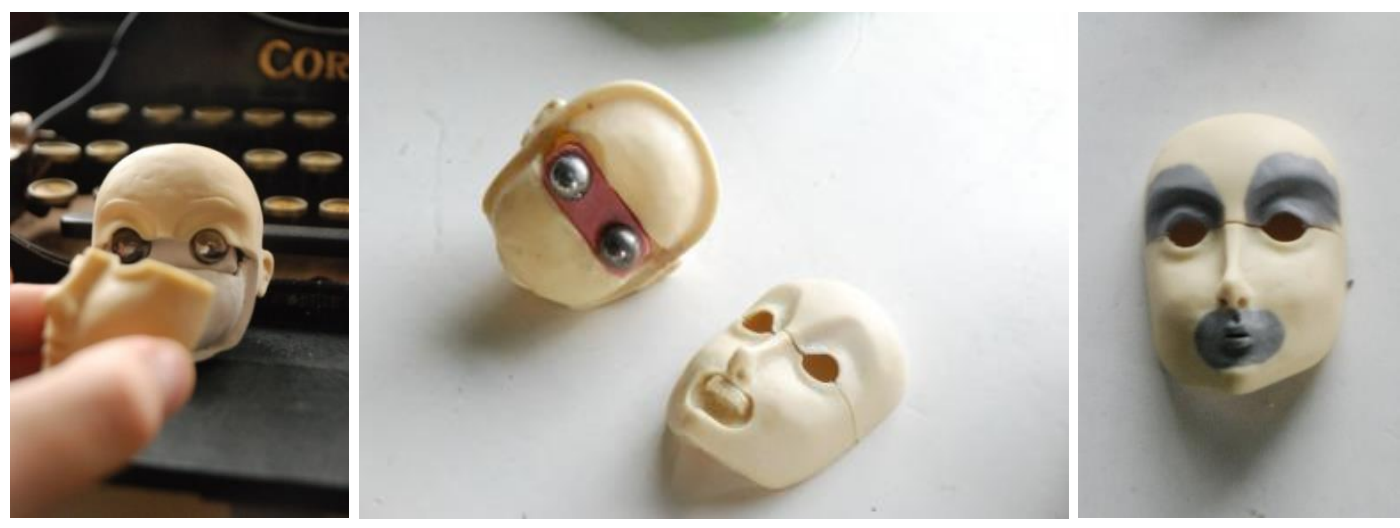

A peça frontal foi recortada na linha dos olhos, tendo o material retirado na área da sobrancelha, deixando uma cavidade, e na área da boca, esculpindo uma arcada dentária superior, figura 02. Foram criados moldes destas peças em resina $F 16$ e produzidas várias réplicas. Nestas réplicas foram esculpidas as expressões da personagem com Super Sculpey. Um procedimento totalmente artesanal. Depois desta etapa finalizada as peças passaram pelo processo de cozimento em forno, acabamento com a massa para pequenas correções da Sherwin Williams e lixadas com lixa d'agua. Foi colocado primer e uma carga de pintura automotiva. Por fim, foi passado o verniz brilhante e depois, por último, o verniz fosco, figura 03.

Figura 03: Processos de pintura das expressões da personagem. (usado com a permissão de Joseph).
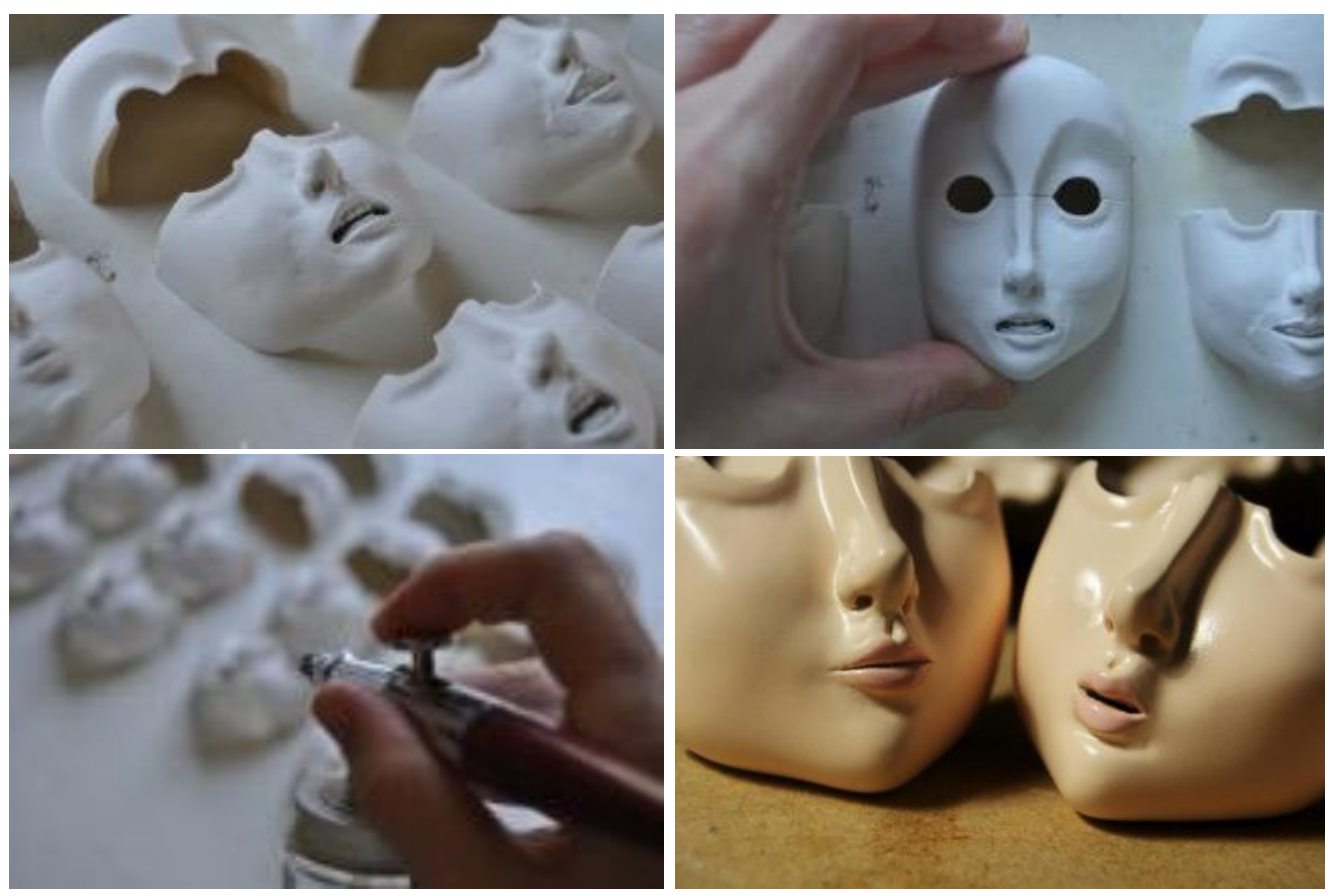

Nys revela em seu blog que em agosto de 2012 nasceu à parceria com o LIM (Laboratório Integrado Multimídia) da UDESC (Universidade do Estado de Santa Catarina), espaço equipado para gravação e edição de som e vídeo, junto com um set de filmagem instalado dentro do Sapiens Parque, em Florianópolis. Agora o uso da tecnologia entra no processo de criação das expressões de substituição. O diferencial nesta etapa de produção são os rostos 
feitos em peças prototipadas em $A B S$ (material moldável através de calor) na impressora $3 D$ UPrint SE, do LIM.

As primeiras modelagens no programa $3 D$, figura 04 , foram feitas do personagem Jordão. As máquinas de prototipagem rápida possuem diferentes tipos de processos na construção de protótipos, pois é através da deposição de materiais que os modelos são construídos progressivamente por camadas. Como cita Fernando J. S. Felício, esses processos "[...] podem ser divididos em três categorias, de acordo com os seus métodos de alimentação: sistemas de base líquida, de base sólida e por último de base em pó [...]" (VOLPATO, 2007, apud FELÍ́CIO, 2012 , p. 50). As impressões em $A B S$, figura 05, são feitas em camadas de plástico. O que acaba acontecendo muitas vezes é que o material pode descolar trazendo dificuldades para o acabamento das peças.

Figura 04 (superior): Modelagem das expressões 3D do personagem. Figura 05 (inferior): Peças de impressão em $A B S$. (usado com a permissão de Joseph).
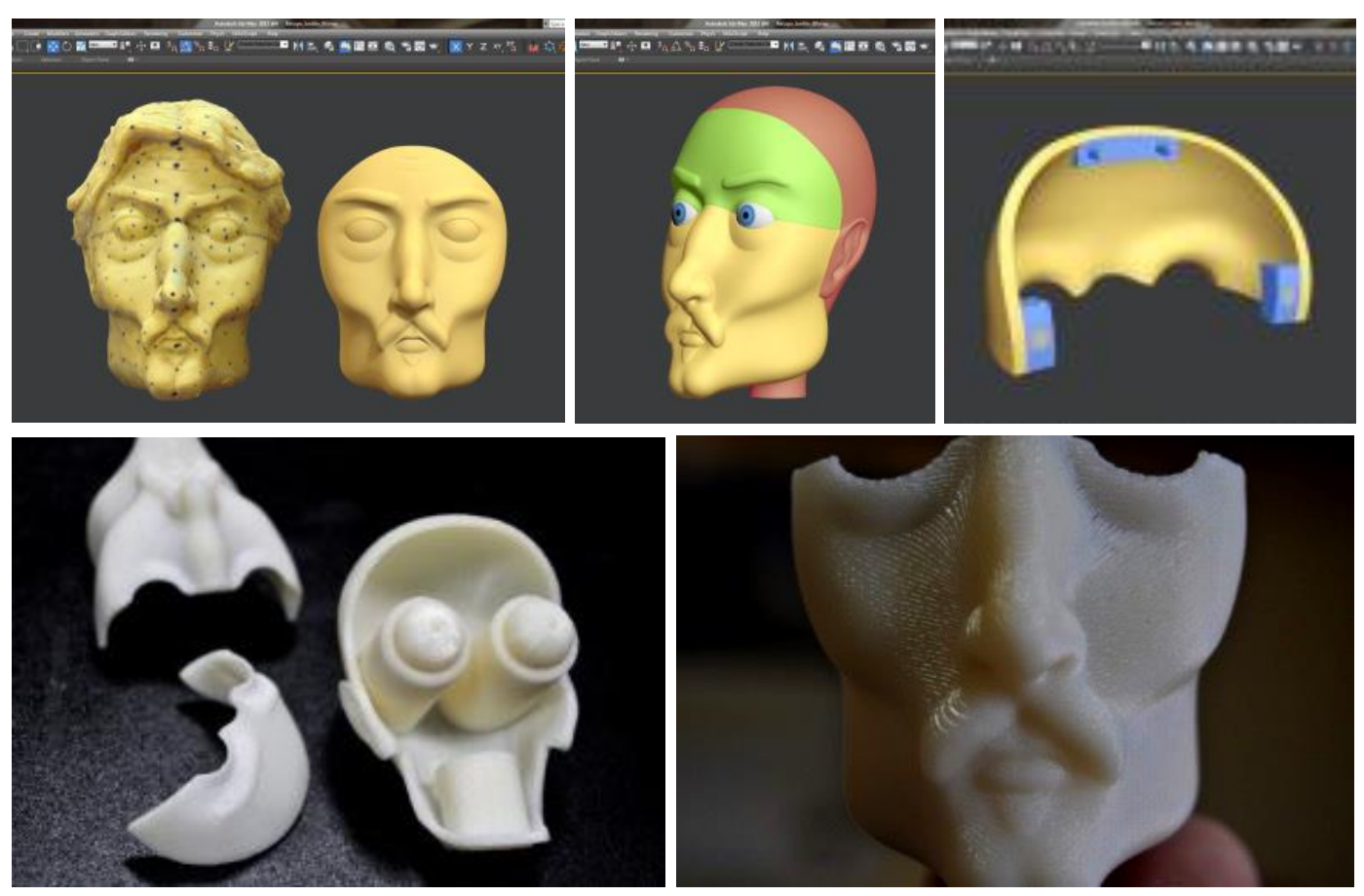

Logo em julho de 2013 o processo sofreu a sua última alteração até o presente momento. Nys conta em entrevista: "Nós íamos fazer todos os rostos em ABS, até que apareceu a incrível parceria com a AGIL 3D." (Nys, 2017). A AGIL 3D é uma empresa de prototipagem rápida de Ribeirão Preto, São Paulo, que possui uma impressora 3D zprint650 que imprime a cores. Essa novidade permitiu ao curta-metragem Almofada de Penas ter peças de encaixes prototipadas coloridas, sem ter o trabalho de pintar cada uma das peças a mão. As peças são feitas a partir da impressão em sílica e só possuem $1 \mathrm{~mm}$ de cor. Este fator torna o trabalho minucioso já que, segundo Nys: "Quanto mais tu lixar, mais perto do branco tu vai chegar. Quando menos tu lixar, mais marcas de impressão vão ter." (Nys, 2017). Quanto menor a espessura da peça, mais fácil de danifica-la. A etapa mais problemática da impressão 3D, neste projeto, foi o acabamento de lixa. Devido à fragilidade das peças, resultou na quebra de algumas. As primeiras peças de impressão da personagem Alicia estavam tão frágeis e porosas que acabaram sendo descartadas e refeitas. A segunda impressão não deixou de ser frágil, e a equipe do curta-metragem contactou duas restauradoras de arte, Ana Terra e a Katherini, para desenvolver o acabamento das peças, relata Nys em entrevista. A utilização de luvas e máscara é sempre necessária para manusear a escultura. Se a peça for segurada sem utilizar a luva, a gordura da mão encosta na peça e a veda, não deixando absorver a resina. Esta resina é basicamente uma super cola, que serve para proteger a peça e deixa-la mais resistente. O processo é extremamente rápido, tóxico e caro, precisando de atenção em muitos detalhes: se a peça não for totalmente coberta pela resina, as áreas sem proteção podem sofrer com a umidade e danificar. A resina precisa ser secada com um papel toalha 


\section{CIDI 2017

intermediário, pois o excesso dela deixa a peça com brilho. O importante é secar a escultura rapidamente para deixa-la fosca. É preciso ter cuidado para secar a peça uniformemente, não deixar que um material em excesso se forme de um lado e escorra manchando o outro.

Visando sempre proteger a parte da escultura que vai aparecer na fotografia.

Mesmo que esta etapa de prototipagem rápida permita imprimir peças inteiras e únicas para cenas do filme (como na produção do filme Coraline, 2009), o motivo para o recorte do rosto ser feito em testa e boca foi para possibilitar um maior número de combinações nos diálogos e expressões, já que o número de peças é limitado devido ao orçamento. O kit de peças da personagem Alicia contém 61 impressões. Estas se dividem em 18 testas, 35 bocas, 2 nucas e 6 rostos inteiros, figura 10. Pensando na criação dos diálogos, foram impressos todos os visemas e emoções específicas de cada personagem que vão aparecer no conto:

Figura 10: Rostos de impressão $3 D$ coloridos. (usado com a permissão de Joseph).
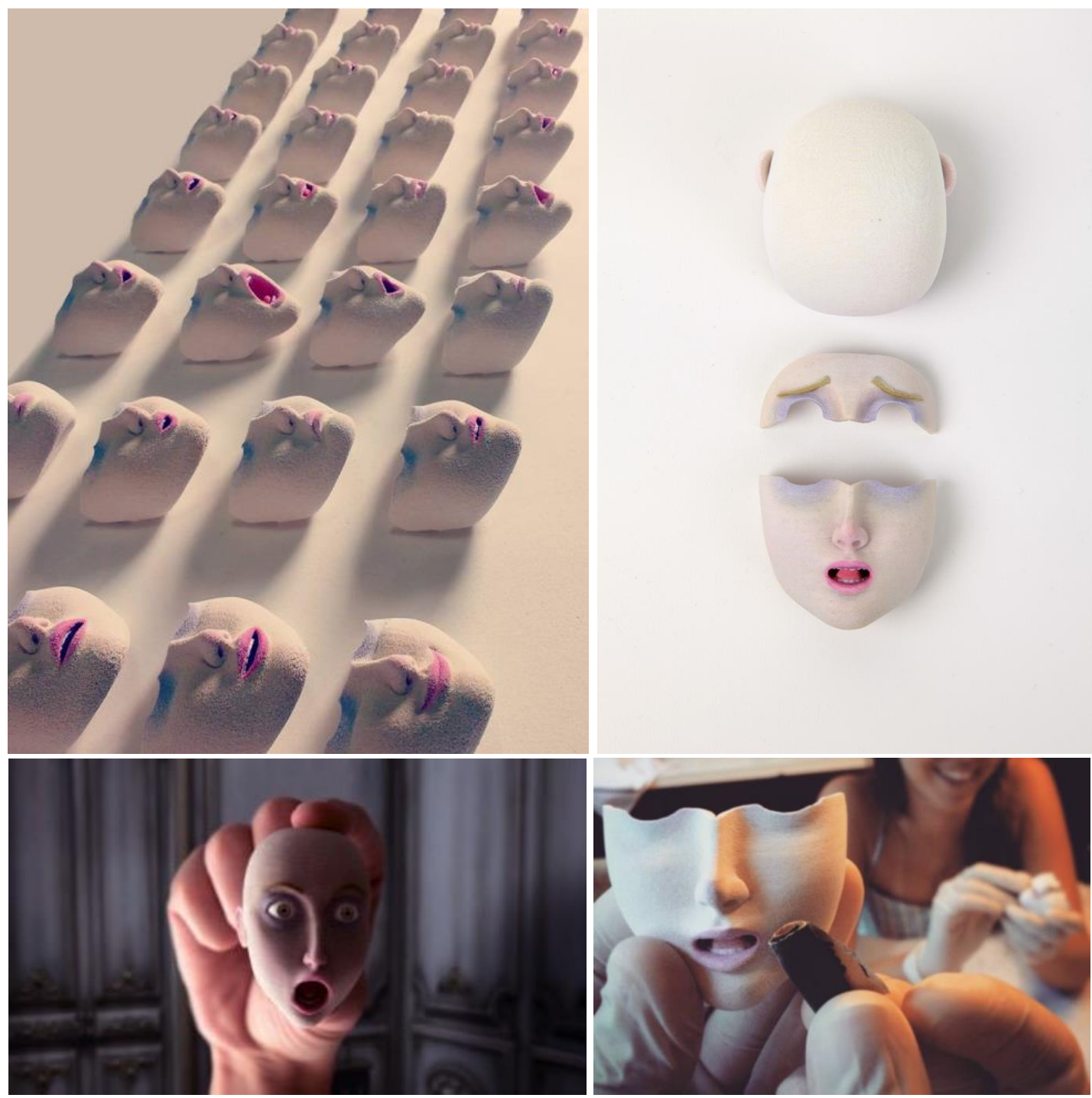

Atualmente as peças de substituição do rosto de Alicia encontram-se catalogadas prontas para a animação. Elas estão armazenadas em um ambiente climatizado, mantendo-as intactas para não sofrerem com mudanças bruscas de temperatura e umidade.

\section{Análises da prototipagem rápida na personagem Alicia}

Neste tópico das análises, partimos do que já foi apresentado no processo de construção das faces da personagem para então observar o resultado final obtido com a prototipagem 
rápida, comparando-o com a etapa de criação a partir dos moldes artesanais. A releitura do conto de Horácio apresenta a personagem Alicia enfrentando uma grave doença após seu recente casamento com Jordão. Toda essa dor e sofrimento enfrentados por Alicia foram levados em consideração na construção do design da personagem. O roteiro surge como um gráfico, onde as informações contidas na narrativa precisam ser comunicadas visualmente para um determinado publico. Um dos elementos principais que ajudam a contar uma história é o personagem. Ele precisa cativar e transmitir informações ao espectador. Isso remete ao design da informação, conforme relata Marcos Balster Fiore Correia, com sua finalidade de auxiliar "[...] no entendimento da informação e na assimilação da informação, ou seja, na sua transformação em conhecimento" (2009. p.191) através da seleção, organização e apresentação da informação para um publico. Deixando evidente a essência e mantendo somente o que for relevante. Deste modo, o objetivo, sobretudo, é conseguir completar satisfatoriamente a tarefa de transmitir as informações presente no roteiro com clareza. $\mathrm{Na}$ construção da Alicia houve um estudo de ambientação do período histórico da narrativa, buscando delinear uma jovem que vive no início do século XX e que passa por mudanças psicológicas e físicas, a partir de um casamento infeliz.

Figura 06 (esquerda): Rosto de Alicia criado a partir de moldes de resina F16. Figura 07 (direita): Rosto de Alicia criado a partir da prototipagem rápida em sílica. (usado com a permissão de Joseph).
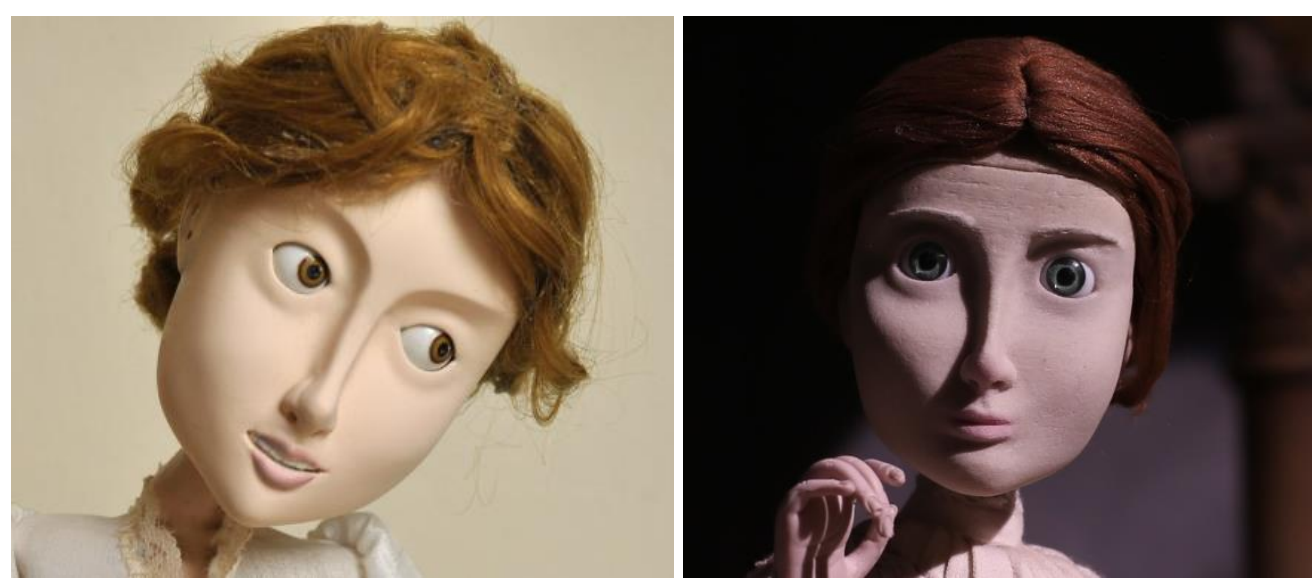

Utilizando como referência os princípios de contraste e afinidade de linhas e formas definidas por Bruce Block (2010) vamos analisar o design de personagem final do rosto de Alicia na prototipagem rápida, figura 07 , com o resultado anterior, obtido através dos moldes de resina F16, figura 06. Block traz em seu livro A narrativa Visual (2010) a ideia de que um filme é composto por elementos visuais tais como: cor, linha, forma, tom, ritmo e movimento que são articulados para gerar uma significação intrínseca a estrutura narrativa. Ao expor estes componentes o autor traz as características principais das formas que são decorrentes das três formas básicas como: o triângulo, o retângulo e o círculo. Quando se junta linhas diferentes em um personagem que irá compor um frame $e^{5}$ de um filme, suas qualidades reverberam em sensações visuais. Quanto mais diversas as qualidades dos elementos visuais mais contraste elas irão gerar, resultando em imagens intensas. Assim como formas com qualidades aproximadas podem acarretar em composições com afinidades entre si. Desta maneira, segundo Block a afinidade e o contraste são decorrentes das relações entre os elementos visuais que acarretam em percepções e significações diversas.

Podemos observar que a forma básica presente no design do formato do rosto de Alicia, figura 07 é composta por um retângulo com algumas linhas inferiores diagonais. A linha alongada do rosto faz contraposição e contraste com os olhos, que são mais arredondados. $O$ nariz está em afinidade com o formato do rosto por terem linhas quase verticais. Queixo e bochechas ganharam mais volume, deixando formas mais curvas em comparação ao primeiro rosto, figura 06. Ele apresenta uma forma geral mais orgânica sem contrastes intensos entre as linhas que compõem o formato do rosto em relação as linhas que delineiam os olhos, nariz e

\footnotetext{
${ }^{5}$ Frame é cada um dos quadros ou imagens fixas de um produto audiovisual.
} 
boca. Em síntese ela apresenta um rosto com formas suaves e sem contrastes entre si, se compararmos ao primeiro modelo. A incidência da luz no material faz com que os grãos de textura sejam aparentes, o que traz certa organicidade a pele. Esta textura com porosidade parece torna-la mais humanizada em relação ao primeiro modelo, figura 06, em que observamos uma superfície lisa remetendo a um material sintético, que lembra a plasticidade gerada pelo sistema de impressão em $A B S$ que se caracteriza pela presença de ranhura.

Figura 08 (esquerda): Personagem com o rosto criado a partir de moldes.

Figura 09 (direita): Personagem com o rosto criado a partir da prototipagem rápida. (usado com a permissão de Joseph).
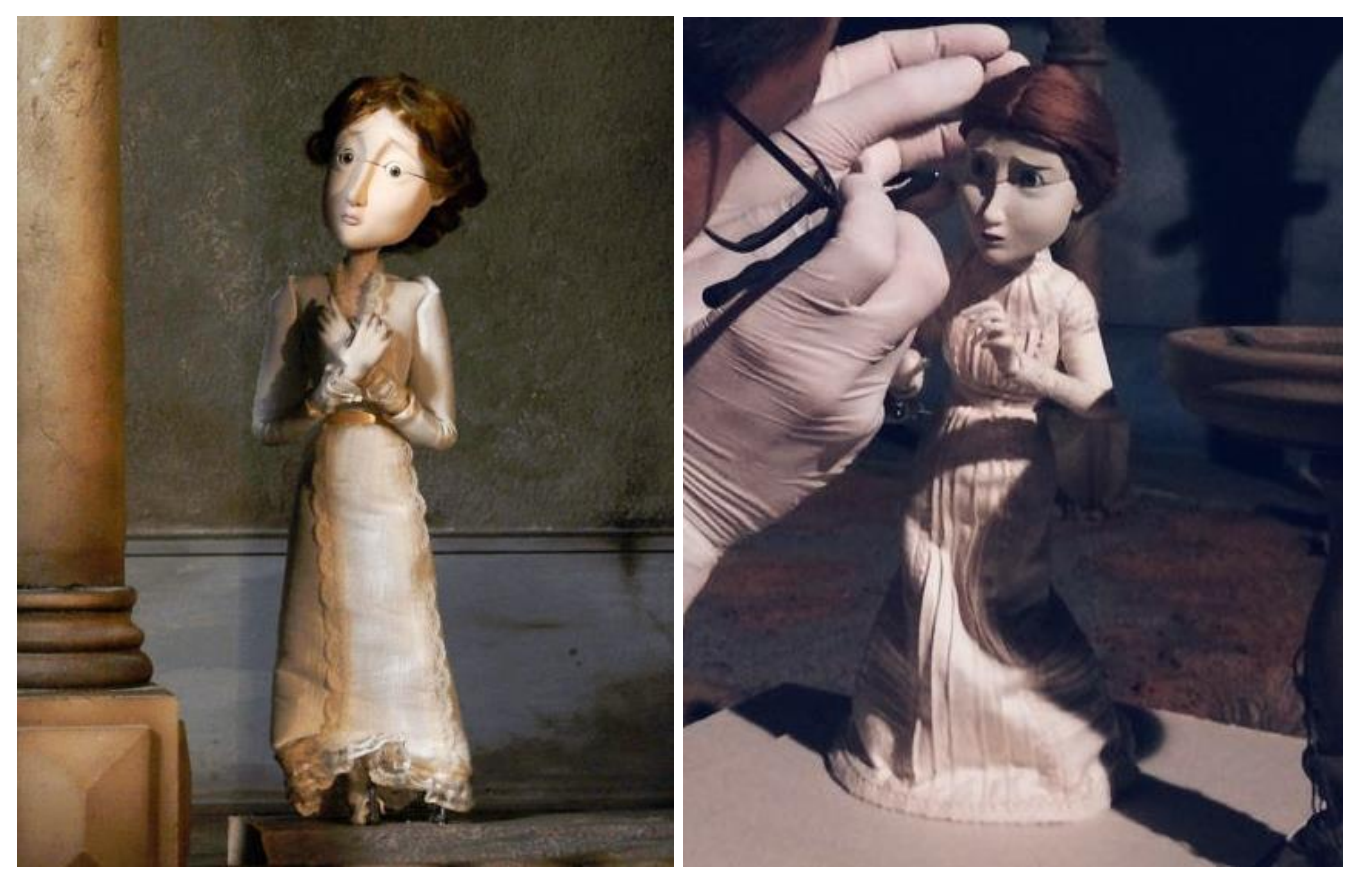

Na concepção do cabelo ambas as versões foram produzidas com materiais sintéticos, mas, observa-se um maior cuidado na escolha do material utilizado na versão prototipada, visando à identidade de um cabelo natural, com reflexos, espessuras e nuances de cores diversas, fora as tonalidades de cor nas bochechas, nariz, pálpebras, olheiras que o artesanal não possui. Além das informações no rosto e cabelo, também faz parte da composição da personagem Alicia seu vestuário. O cuidado em seguir uma unidade na escala dos tecidos e rendas com as proporções da personagem possibilita uma composição uniforme e harmônica, figuras 08 e 09 .

Outro ponto a ser mencionado incide no fato de que o curta-metragem é uma produção independente e possui poucos recursos financeiros. Devido aos custos altos de impressão das peças em prototipagem rápida, não foi possível fazer uma etapa de testes de impressão das expressões. Essa dificuldade em experimentação impossibilitou Nys chegar na perfeição de impressão que queria: sem defeitos na variação de cor, sem áreas rugosas e áreas esbranquiçadas. Mas essas imperfeições se tornam linhas e complexificam em certa medida a imagem, deixando evidente a fisicalidade do material, característica da técnica de stop motion.

\section{Considerações finais}

As observações sobre a protipagem rápida no processo de construção da personagem Alicia no curta-metragem Almofada de Penas revelou-se um método de produção passível a experimentações e pôde assumir características estéticas próximas a um acabamento artesanal. Considerando as diversas máquinas de prototipagem que imprimem com materiais variados apresentando características distintas no resultado final, tais como: textura, brilho, cor e técnicas diferentes de finalização da peça. Tais aspectos nos levam as especificidades da animação em stop motion com prototipagem rápida. Os tipos de impressão utilizada, sílica ou $A B S$, irão acarretar em materialidades e características estéticas específicas às peças da animação. Neste momento da produção do Almofada de Penas, que se encontra em processo 
de realização, percebemos que a presença do grão do material impresso em sílica se faz evidente, assim como reverbera nas características conceituais da personagem Alicia.

A etapa de criação dos personagens se mostra decisiva em um projeto. O visual precisa transmitir claramente a informação da narrativa. Assim, neste processo de prototipagem rápida na criação das expressões da Alicia, percebemos um domínio do projeto tridimensional que direciona e guia as etapas seguintes. A especificidade deste método de produção na animação reside no fator projetual do personagem. Mesmo podendo ter as possíveis falhas na impressão, a modelagem em software $3 D$ possibilita ver e modificar as expressões até chegar no nível mais próximo do resultado planejado. Podemos dizer que a impressão $3 D$ surge como um mecanismo tecnológico do design da informação. Ela projeta na construção dos personagens as informações que o roteiro precisa transmitir. É através da escultura, com suas texturas, paletas de cor e forma provindas do material escolhido para a impressão que as caraterísticas da narrativa se tornam explícitas. Esta questão nos leva as possibilidades de escolha do diretor diante do material impresso. É possível manter suas características físicas, materiais, tais como porosidade, lisura, brilho, assim como é concebível a animação mascarar as características do material impresso através da utilização de efeitos visuais em pós-produção.

\section{Referências}

\section{Bibliográficas}

ALGER, Jed. 2014. The Art and Making Of The ParaNorman. Sam Francisco: Choranicle Books.

BLOCK, Bruce A. 2010. A narrativa visual: Criando a estrutura visual para cinema, TV e mídias digitais. São Paulo:Elsevier, Tradução da 2ª Edição.

CORREIA, Marcos B. F. 2009. A comunicação de dados estatísticos por intermédio de infográficos [recurso eletrônico] : uma abordagem ergonômica. Tese de mestrado em Artes \& Design - Pontifícia Universidade Católica do Rio de Janeiro, Brasil.

FELÍCIO, Fernando J. S. 2012. Fabricação rápida no design: Uma abordagem na concepção de produto. Tese de mestrado em Design de Equipamento - Universidade de Lisboa, Portugal.

LIPSON, H.; KURMAN, M. 2013. Fabricated: The New World of 3D Printing. Indianapolis: John Wiley \& Sons.

NYS, Joseph Specker. [Blog] Almofada de Penas. <http://almofadadepenas.tumblr.com/> 10/07/ 2017.

PRIEBE, Ken. A. 2010. The Advanced Art of Stop-Motion Animation. Vancouver: Delmar Cengage Learning.

PURVES, Barry J. C. 2010. Stop-motion - Col. Animação Básica. Porto Alegre: Bookman.

RASTRO, Agencia. 2014. Minhocas: elas estão de volta ao nosso festival. Anima Mundi. <http://www.animamundi.com.br/pt/blog/minhocas-elas-estao-de-volta-ao-nosso-festival/> 10/07/ 2017.

SHAW, Susannah. 2012. Stop Motion: Técnicas Manuais Para Animação Com Modelos. Rio de Janeiro: Elsevier, Tradução da $2^{\mathrm{a}}$ Edição.

\section{Fílmicas}

A vingança do câmeraman. Ladislas Starevich. Rússia, 1912. 13 minutos, cor. Título original: Mest kinematograficheskogo operatora.

Afinal, o que querem as mulheres? Luiz Fernando Carvalho. Brasil, 2010. 6 episódios, 40 minutos, cor.

Almofada de Penas. Joseph Specker Nys. Brasil, 2017. 15 minutos, cor. 
Coraline e o Mundo Secreto. Henry Selick. Estados Unidos, 2009. 100 minutos, cor. Título original: Coraline and The Secret World.

James e o Pêssego Gigante. Henry Selick. Estados Unidos, 1996. 84 minutos, cor. Título original: James and the Giant Peach.

Les 400 Farces du Diable. George Méliès. França, 1906. 17 minutos, cor.

Minhocas. Paolo Conti. Brasil, 2013. 82 minutos, cor.

O Estranho Mundo de Jack. Henry Selick. Estados Unidos, 1993. 76 minutos, cor. Título original: The Nightmare Before Christmas.

Puppetoons George Pál. Estados Unidos, 1945. 19 episódios. 7 minutos, cor.

\section{Sobre os autores}

Nurian Brandão, Ba, UFPel, Brazil, <nuh.brandao@gmail.com>

Vivian Herzog, MSc, UFPel, Brazil, <vivianherzog@gmail.com>

Flavio Andalo, MSc, UFSC, Brazil, <fla2@uol.com.br>

Milton Luiz Horn Vieira, Dr, UFSC, Brazil, <milton@cce.ufsc.br> 